30. Kick JD, Rosengard BR, Merz WG, Stuart RK, Hutchins GM, Saral R. Fatal disseminated candidiasis due to amphotericin Bresistant Candida guilliermondii. Ann Intern Med 1985;102:6768.

31. Seidenfeld SM, Cooper BH, Smith JW, Luby JP, Mackowiak PA. Amphotericin B tolerance: a characteristic of Candida parapsilosis not shared by other Candida species. J Infect Dis 1983;147:116-119.

32. Newman SL, Flanigan TP, Fisher A, Rinaldi MG, Stein M, Vigilante K. Clinically significant mucosal candidiasis resistant to fluconazole treatment in patients with AIDS. Clin Infect Dis 1994;19:684-686.

33. Sanguineti A, Carmichael JK, Campbell K. Fluconazoleresistant Candida albicans after long-term suppressive therapy. Arch Intern Med 1993;153;1122-1124.

34. Cameron ML, Schell WA, Bruch S, Bartlett JA, Waskin HA, Perfect JR. Correlation of in vitro fluconazole resistance of Candida isolates in relation to therapy and symptoms of individuals seropositive for human immunodeficiency virus type 1.
Antimicrob Agents Chemother 1993;37:2449-2453.

35. Boken DJ, Swindells S, Rinaldi MG. Fluconazole-resistant Candida albicans. Clin Infect Dis 1993;17:1018-1021.

36. Ruhnke M, Eigler A, Tennagen I, Geiseler B, Engelmann E, Trautmann M. Emergence of fluconazole-resistant strains of Candida albicans in patients with recurrent oropharyngeal candidosis and human immunodeficiency virus infection. J Clin Microbiol 1994;32:2092-2098.

37. Chang SC, Hsieh WC, Luh KT. Resistance to antimicrobial agents of common bacteria isolated from Taiwan. Int $J$ Antimicrob Agents 1994;4:143-146.

38. Cohen ML. Epidemiology of drug resistance: implications for a post-antimicrobial era. Science 1992;257:1050-1055.

39. Neu HC. The crisis in antibiotic resistance. Science 1992;257:1064-1073.

40. Kunin CM. Resistance to antimicrobial drugs-a worldwide calamity. Ann Intern Med 1993;118:557-561.

41. Pfaller MA. Epidemiology and control of fungal infection. Clin Infect Dis 1994;19(suppl 1):8-13.

\title{
Nosocomial Hepatitis B Outbreak Despite New Design of Finger-Stick Device
}

\section{Gina Pugliese, RN, MS Martin S. Favero, $\mathrm{PhD}$}

Finger-stick devices are used widely for capillary-blood sampling for glucose monitoring in patients with diabetes. The $\mathrm{CDC}$ recently reported two outbreaks of hepatitis B virus (HBV) infection, involving four patients in an Ohio nursing home and three inpatients in a New York City hospital, respectively. In both outbreaks, HBV transmission was associated with the use on multiple patients of spring-loaded finger-stick devices. In one outbreak, the lack of glove change between patients may have played a role in transmission of HBV.

The Ohio nursing home routinely used the Monojector $\mathrm{AE}$ (Sherwood-Davis and Geck, St Louis, MO), a pen-like device with a lancet and an end cap that rests on the patient's finger during blood sampling. Nursing personnel routinely changed the lancet between residents, but, after the initial supply of end caps for each device had been used, end caps no longer were changed. It is believed that the end cap, which rests on the finger during blood sampling, can be contaminated with blood after the lancet pierces the skin.

The package insert for this device indicates that both the lancet and end cap should be replaced after each use.
The fact that these end caps were not changed routinely suggests that HBV transmission occurred through exposure of subsequent patients to residual blood on the end caps.

After recognition of this outbreak and implementation of individual finger-stick devices for each patient, no additional cases were detected.

Finger-sticks at the New York City hospital were performed with the Glucolet AE 2 (distributed by Miles Elkhart Inc, Elkhart, IN), a pen-like device with a disposable lancet and end cap assembly. The lancet was changed after each finger stick, but the pen-like lancet-holding device was used for multiple patients. Finger sticks usually were performed by nursing staff who started at one end of the ward and moved from room to room. Improper use of the finger-stick device (eg, reusing disposable parts) was not reported by the nursing staff; however, nursing reported observing that hands were not always washed nor gloves changed between patients and that used lancet caps were placed in the same box as unused lancet caps. Although the combined lancet and end cap assembly was changed after each patient use, the pen-like lancet-holding device, which was shared and not cleaned between patients, may have served as a vehicle for transmission. Transmission also may have occurred via blood contam- ination of the nurses' gloves or unused lancet caps. After implementation of a completely disposable, nonreusable finger-stick device, routine handwashing, and glove changing after contact with each patient, no additional cases have been identified.

Outbreaks of HBV infection associated with the use of springloaded finger-stick devices on multiple patients have been reported in the United States and elsewhere. Various designs of these devices are cleared by the FDA, but all of them function similarly. After an outbreak in a hospital in California involving 26 patients, the $\mathrm{CDC}$ and the FDA issued recommendations for the safe use of spring-loaded finger-stick devices, including, optimally, using a separate device for each patient. The results of these investigations reemphasize the need to restrict use of finger-stick capillary-blood sampling devices to individual patients and to discard used parts appropriately. In addition, when medical procedures are performed on multiple patients, gloves should be changed after contact with each patient.

FROM: Centers for Disease Control and Prevention. Nosocomial hepatitis B virus infection associated with reusable fingerstick blood sampling devices-Ohio and New York City, 1996. MMWR 1997;46(10):217221. 